\title{
Systematic Evaluation of Current Control Devices Used by People with Intellectual Disabilities in Non-Immersive Virtual Environments
}

\author{
P.J. STANDEN, B.Sc., Ph.D., ${ }^{1}$ D.J. BROWN, M. Eng., Ph.D., ${ }^{2}$ \\ N. ANDERTON, B.A. ${ }^{3}$ and S. BATTERSBY, B.Sc. ${ }^{2}$
}

\begin{abstract}
Virtual environments have a role to play in facilitating the acquisition of living skills in people with intellectual disabilities, improving their cognitive skills and providing them with entertainment. However, the currently recommended devices to allow navigation in and interaction with the environments are difficult to use. Using a methodology established in an earlier study, the study aims to systematically document the performance of users with the currently recommended devices in order to (i) inform the design of a usable control device or devices and (ii) act as a baseline against which they can be evaluated. 40 people with severe intellectual disabilities aged 21-67 years used four environments with an equal number of sessions with the different devices being evaluated. Results indicate that when forward movement is provided by the software using the mouse for both navigation and interaction allows better performance both initially and after exposure than using the fire button on the joystick. When the user had to initiate forward movement with the navigation device, the joystick allowed better performance than the arrows on the keyboard. Preventing slippage of the joystick base would make its use much easier and it is suggested that separate devices are retained for navigation and interaction.
\end{abstract}

\section{INTRODUCTION}

$\mathrm{O}$ NE SECTION OF SOCIETY that stands to gain considerably from advances in information technology is those with intellectual disabilities. Estimates vary, but in most developed countries prevalence figures are around 30 per thousand, $, 1,2$ and rates are increasing. ${ }^{3}$ People with intellectual disabilities are amongst the most socially excluded and vulnerable groups and the intention of current policy $^{1}$ is to enable them to have as much choice and control as possible over their lives, be involved in their communities and to make a valued contribution to the world at work.

Virtual environments (VE) have a role to play in this process. ${ }^{4}$ Initial work suggests that they are effective in facilitating the acquisition of living skills in children with severe intellectual disabilities. ${ }^{5}$ Their three-dimensional nature allows the creation of ecologically valid settings to promote activities which they have little opportunity to practice. ${ }^{6} \mathrm{Fi}-$ nally, they can provide an engaging activity for people who are frequently underoccupied and denied real world opportunities. ${ }^{7}$

1Division of Rehabilitation and Ageing, University of Nottingham, Nottingham, United Kingdom.

${ }^{2}$ School of Computing and Mathematics, Nottingham Trent University, Nottingham, United Kingdom.

${ }^{3}$ City Hospital, Nottingham, United Kingdom. 
The work carried out so far has employed nonimmersive VE where the environment is displayed on an ordinary computer monitor. Utilising control devices, the user's tasks are to navigate their way around the environment and interact with it. Navigation can be on a continuum between automatic, where the user is taken through the environment without any action on their part and self-controlled. Most environments are semi-automatic (i.e., constrained by the software). So, for example, they may employ terrain tracking where the user can only move on a horizontal plane. Interaction can activate objects (select item on supermarket shelf and move it into trolley), move them or cause one object to interact with another (e.g., put key in lock). These latter two functions would involve drag and drop.

A variety of devices are employed for navigation and interaction. Many games that endeavour to represent a three-dimensional world can be navigated using the arrow keys but for users with intellectual disabilities it is recommended that a joystick limited to two degrees of freedom had the greatest utility. ${ }^{8,9}$ The more functions a device possesses, the more difficult it is to operate. So, for example, when using a spaceball which has six degrees of freedom, the user with intellectual disabilities frequently becomes lost. For interaction tasks, if drag-and-drop is not required, the touchscreen and mouse have been found to be equally effective, although touch-screens can require frequent calibration. ${ }^{9}$

However, even the preferred devices of joystick for navigation and two button mouse for interaction can be challenging to use. One reasons for this is the level of cognitive ability of the users as they have difficulty remembering what tasks are accomplished by each device and in moving from one device to the other as many used the same (dominant) hand for both devices. ${ }^{10}$ Additionally many people with intellectual disabilities have fine motor difficulties as they suffer from conditions where damage has been caused to the central nervous system, such as cerebral palsy, multiple sclerosis, muscular dystrophy and dyspraxia. They therefore find the devices difficult to control. ${ }^{11}$

With problems like these, users can become frustrated and demotivated and fail to benefit from the advantages of using VE. This study set out to systematically document the performance of users with the currently recommended devices using a methodology established in an earlier study. The intention was to collect information which could then be used to inform the design of a usable control device or devices and to act as a baseline against which they can be evaluated.

\section{METHODS}

\section{Design}

Performance data were collected on the currently used control devices which could be compared with similar data collected on any prototype developed. To reduce the effect of learning on performance, participants were allowed several practice sessions with the currently used devices before data collection started and the order in which devices were used was balanced.

\section{Participants}

Forty people (17 men, 23 women) aged 21-67 years who regularly attended a day centre for people with intellectual disabilities volunteered to take part and all met the requirement of having sufficient visual ability to see the VE on the computer monitor. They were selected to represent a wide range of ability within the severe classification and on measures of verbal (British Picture Vocabulary Scale) and non verbal (Ravens matrices) IQ, they all scored within the severely disabled range. For motor control and co-ordination (Quick Neurological Screening Test II), five were in the normal range, 27 showed moderate discrepancy and five showed severe discrepancy.

\section{Virtual environments}

Four training VE were constructed in order to evaluate the currently used devices as well as any prototypes that were developed (Fig. 1). They were built using 3D Studio or Plasma and then imported into Director so that all interactive elements and lighting could be coded in. In order to increase their attractiveness to users and facilitate the acquisition of navigation and interaction skills they were all designed using game format in that they consisted of varying levels of difficulty with access to each level only allowed once the correct level of performance had been achieved at the previous level. Additionally, feedback in the form of scores was available to the user. Each environment constrained different possibilities in order to test the most commonly required functions of the control devices in educational VE but without presenting the user with too many options initially. So the first two environments encountered did not require a device to effect forward movement and one did not require interaction. When interaction was required, it was limited to activating an object. In two environments, the same device was used for both navi- 

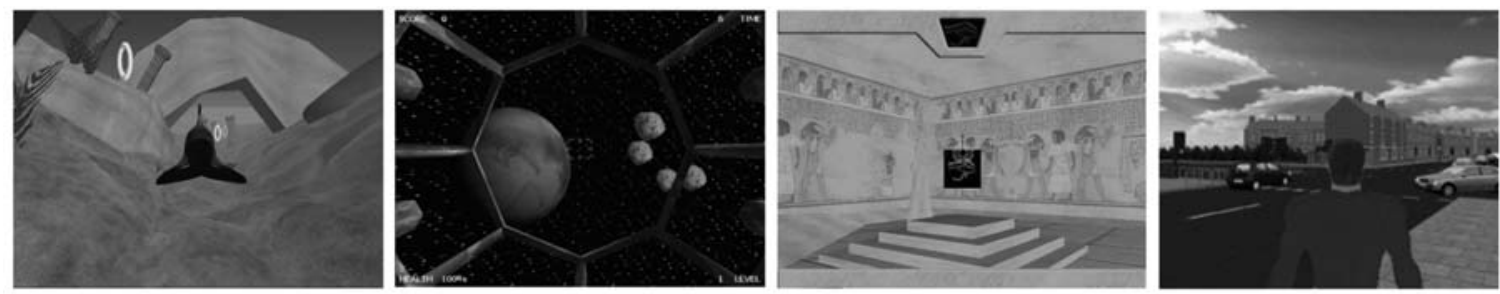

FIG. 1. Screenshots from the four virtual environments.

gation and interaction. In three of the environments the user followed an avatar. The software also collected information on task achievement (scores), time taken and collisions.

Table 1 summarizes the characteristics of each environment.

\section{Data collection}

Data collection took place in the day centre attended by the participants. Participants had sessions scheduled for once a week, which lasted a maximum of $30 \mathrm{~min}$ but could be terminated earlier if they wished. One of the researchers (N.A.) sat alongside them to give assistance and encouragement. The devices used were a standard three-axis games joystick (Microsoft sidewinder, Saitek ST200 ambidextrous): standard two-button mouse and keyboard. The order in which they worked through the environments was the same for each participant starting with the environment which required fewest functions from the control devices. Participants had several practice sessions with each environment with each device before data were collected and the order in which they used the different devices varied between participants to counteract any remaining effects of increasing familiarity on performance. Each session was recorded on videotape and videotapes were analysed using a method established in an earlier study ${ }^{10}$ from which the amount of physical assistance given by the researcher could be recorded. This was described as concerning the devices (whether for navigation or interaction) or the environment. The researcher also kept a diary to record any other information that might be useful but that would not be picked up by video analysis or the software data gatherer. Computer collected data (scores and collisions) were adjusted for length of session. Video collected data were expressed as a percentage of session duration.

\section{Statistical analysis}

Comparisons between the devices were made using the Wilcoxon test for paired data. As most data were skewed in their distribution, medians are displayed in the tables and each participant's result with one device was compared to their result with each of the other devices in a two group comparison using the Wilcoxon test for paired data. While this increased the number of comparisons made, it showed exactly where differences between devices occurred.

\section{RESULTS}

\section{Environments where forward movement was provided}

Mouse versus joystick. Even after having several practice sessions, using the mouse allowed participants to gain significantly higher median scores than

TAble 1. Characteristics of Training ENVIRONMENTS

\begin{tabular}{|c|c|c|c|c|}
\hline & $\begin{array}{l}\text { Devices used for } \\
\text { forward } \\
\text { movement }\end{array}$ & $\begin{array}{c}\text { Devices used for } \\
\text { up/down and } \\
\text { left/right } \\
\text { movement }\end{array}$ & $\begin{array}{l}\text { Devices tested } \\
\text { for interaction }\end{array}$ & $\begin{array}{l}\text { Follow } \\
\text { avatar }\end{array}$ \\
\hline Asteroids & None required & $\begin{array}{l}\text { Joystick } \\
\text { Mouse }\end{array}$ & $\begin{array}{l}\text { Joystick button } \\
\text { LH mouse button }\end{array}$ & No \\
\hline Dolphins & None required & $\begin{array}{l}\text { Joystick } \\
\text { Arrow keys }\end{array}$ & None required & Yes \\
\hline $\begin{array}{l}\text { Temple, road } \\
\text { crossing }\end{array}$ & $\begin{array}{l}\text { Joystick } \\
\text { Arrow keys }\end{array}$ & $\begin{array}{l}\text { Joystick } \\
\text { Arrow keys }\end{array}$ & $\begin{array}{l}\text { LH mouse button } \\
\text { LH mouse button }\end{array}$ & Yes \\
\hline
\end{tabular}


Table 2. Median Adjusted Scores and Median Percentage of Session Spent by Tutor Giving ASSISTANCE FOR ASTEROIDS

\begin{tabular}{lrrrrr}
\hline & \multicolumn{3}{c}{ Joystick } & & \multicolumn{2}{c}{ Mouse } \\
\cline { 2 - 3 } & Trial 1 & Trial 2 & & Trial 1 & Trial 2 \\
\hline Score & 4.24 & 4.05 & & 7.09 & 12.23 \\
Assistance with navigation & 25.96 & 10.25 & & 4.46 & 0 \\
Assistance with interaction & 2.34 & 0 & 1.59 & 0 \\
\hline
\end{tabular}

with the joystick on both the first $(p<0.006)$ and the second $(p<0.001)$ trials on which data were collected (Table 2). The practice sessions did not appear to have totally eliminated learning as scores were even higher with the mouse on the second session from which data were collected. The mouse also performed better than the joystick on the measure of tutor assistance. By the second trial using the mouse, they needed significantly less assistance when navigating on both the first $(p<0.002)$ and second $(p<0.001)$ trials than they did with the joystick. The amount of assistance with interaction was significantly lower on the second trial with the mouse $(p<0.007)$.

Keyboard versus joystick. In contrast to the previous set of results, the joystick performed well in comparison to use of the arrows on the keyboard. Participants gained significantly higher scores (Table 3) with the joystick than with the keyboard on all trials on which data were collected (first: $p<$ 0.001 ; second: $p<0.001$; third: $p<0.005)$. There were no differences between the two devices in collisions but with both devices collisions became more frequent on the third trial probably because participants were concentrating on achieving higher scores and there were no obvious penalties for collisions. No significant differences were found between the devices on assistance given.

Environments where user has to effect forward movement with the navigation device. The joystick also allowed better user performance than the keyboard when the user had to effect forward movement in navigation. Participants were faster with the joystick than the keyboard on each level of Temple
(Table 4) for which data were available and on two of the scenarios (zebra and pelican crossings) in Road Crossing (Table 5). This difference was significant for level $1(p<0.05)$ and level $5(p<0.02)$ of Temple and for the zebra $(p<0.02)$ and pelican crossings $(p<0.01)$. There was no difference between the devices in the rate of collisions.

In terms of help given by the tutor, the advantage of the joystick was not so clear. In Road crossing, participants received less assistance with the joystick than with the keyboard arrows when navigating in two of the scenarios but this was not significant. In contrast more assistance was given with navigation when the joystick was being used in Temple but this difference was only significant on the last three trials (trial 4: $p<0.035$; trial 5: $p<0.007$; trial 6: $p<0.01$ ). Very few users received assistance with interaction when using the joystick in Temple so a comparison of the median percentage of time spent in assistance with interaction only reached significance on the first $(p<0.05)$ level. In Road Crossing the joystick required less assistance than did the keyboard arrows in only one of the two parts of the environment where this was applicable (pelican crossing: $p<0.042$ ).

\section{Additional information}

For all four games, slippage of the base of the joystick was a problem for $25-37 \%$ of participants. Even on the last trial of the Temple when participants had considerable exposure the joystick was slipping for 13 out of 30 people for whom this information was available. The number of people using too much force with the joystick increased from five on the first trial to 13 on the last trial.

Table 3. Median Adjusted SCORes and Collisions for Dolphins

\begin{tabular}{|c|c|c|c|c|c|c|}
\hline & \multicolumn{2}{|c|}{ Trial 1} & \multicolumn{2}{|c|}{ Trial 2} & \multicolumn{2}{|c|}{ Trial 3} \\
\hline & Keyboard & Joystick & Keyboard & Joystick & Keyboard & Joystick \\
\hline Score & 1.42 & 2.97 & 2.05 & 2.72 & 2.00 & 2.75 \\
\hline Collisions & 15.13 & 16.27 & 16. 71 & 15.59 & 21.55 & 21.52 \\
\hline
\end{tabular}


Table 4. Median Time in Minutes to Complete Trials and Median Percentage Of Session Spent by Tutor Giving Assistance for Temple

\begin{tabular}{lcccccc}
\hline & \multicolumn{7}{c}{ Trials } \\
\cline { 2 - 7 } & 1 & 2 & 3 & 4 & 5 & 6 \\
\hline Time & & & & & & \\
$\quad$ Keyboard & 4.11 & 4.08 & 3.43 & 3.19 & 3.54 & - \\
$\quad$ Joystick & 3.24 & 3.31 & 2.29 & 3.03 & 2.85 & - \\
$\quad \begin{array}{l}\text { Assistance with navigation } \\
\quad \text { Keyboard }\end{array}$ & 8.82 & 8.67 & 6.63 & 3.56 & 2.8 & 3.92 \\
$\quad$ Joystick & 15.34 & 14.73 & 11.76 & 10.55 & 10.72 & 8.84 \\
$\quad \begin{array}{l}\text { Assistance with interaction } \\
\quad \text { Keyboard }\end{array}$ & 0.90 & 0 & 0 & 0 & 0 & 0 \\
$\quad$ Joystick & 0 & 0 & 0 & 0 & 0 & 0 \\
\hline
\end{tabular}

\section{DISCUSSION}

When navigation in the virtual environment is in the vertical plane only, use of the mouse allows better performance both initially and after exposure than does the joystick. Participants needed less assistance with both navigation and interaction when using the mouse. As use of the joystick could be avoided by writing forward movement into the software this option should be explored further. The joystick was not at a disadvantage when compared with the arrows on the keyboard as the joystick enabled participants to gain consistently higher scores than they did with the keyboard.

When the user had to initiate forward movement with the navigation device, the joystick permitted better performance than did the arrows on the keyboard in terms of speed of achieving tasks. However, the joystick is not without its difficulties. In Temple but not Road Crossing users received more assistance with the joystick than they did with the arrows on the keyboard and this may have been due to the difference in complexity of the two environments. Road crossing depicted a familiar and much more predictable environment where movement was required in straight lines with guidance in the horizontal plane of the environment in the form of markings on the road surface and kerbstones. In contrast, the Temple depicted an unfamiliar environment and offered many more directions of travel with more need to integrate information from different views over time thus increasing the possibility of becoming disoriented.12 When using the arrows on the keyboard each key press moves the user forward by a measured amount and this may have reduced the number of occasions on which the user moved so far from their origin that they lost track of where they were in the environment. Additionally, frequent occurrences of the joystick slipping were recorded. If it slips, the researcher or tutor has to hold the base steady and the lack of accurate feedback from the device makes it less likely that the user will learn the appropriate amount of force to exert. When using the joystick, participants required less assistance with interaction even though for these environments a separate device was being used for interaction. This may be because if the navigation device is eas-

Table 5. Median Time in Minutes to Complete Trials and Median Percentage Of Session Spent by Tutor Giving Assistance FOR ROAD CROSSING.

\begin{tabular}{|c|c|c|c|c|c|c|}
\hline & \multicolumn{6}{|c|}{ Trials } \\
\hline & \multicolumn{2}{|c|}{ Zebra crossing } & \multicolumn{2}{|c|}{ Pelican crossing } & \multicolumn{2}{|c|}{ Crossroads } \\
\hline & Keyboard & Joystick & Keyboard & Joystick & Keyboard & Joystick \\
\hline Time & 0.54 & 0.45 & 0.54 & 0.39 & 0.58 & 0.58 \\
\hline Assistance with navigation & 20.34 & 18.14 & 2.86 & 0 & 0 & 0 \\
\hline Assistance with interaction & $\mathrm{N} / \mathrm{A}$ & $\mathrm{N} / \mathrm{A}$ & 5.13 & 3.23 & 6.02 & 6.90 \\
\hline
\end{tabular}


ier to understand and use, the user has more cognitive capacity available to handle the challenge of interaction. Another possible explanation is that users experienced more problems moving between the keyboard and mouse because on returning to the keyboard they needed to remove their gaze from the monitor in order to place their fingers correctly over the arrow keys.

These advantages of the joystick suggest that the most promising design solution would be to modify the basic games joystick to avoid some of the obvious difficulties that participants experienced, for example the slipping of the device over the surface on which it stood. It is more difficult to decide whether the joystick should combine both functions of navigation and interaction or whether separate devices be retained for each function. An evaluation ${ }^{13}$ of a prototype two handed device that combined both navigation and interaction found that young people with intellectual disabilities were confused about which action caused interaction, which navigation. The present study found that the mouse was easy to understand and use for interaction supporting the findings ${ }^{13}$ that for interaction the mouse was quicker to use than a button on her prototype two handed device. This suggests that in having to meet the cognitive requirements of this particular user group, the functions of navigation and interaction should be provided by two separate devices.

In conclusion, when navigation is required in a three dimensional environment the joystick once mastered does allow even some of the most disabled users to achieve better performance. These results suggest that resolving some of the physical difficulties with the joystick may reduce the likelihood of demotivation on initial usage and also allow better performance once use of the device has been mastered.

\section{ACKNOWLEDGMENTS}

This research was carried out with the support of EPSRC award number GR/R21851.

\section{REFERENCES}

1. Department of Health. (2001). Valuing people: a new strategy for learning disability for the $21^{\text {st }}$ century. London: HMSO.

2. Heikura, U., Taanila, A., Olsen, P., et al. (2003). Temporal changes in incidence and prevalence of intellectual disability between two birth cohorts in
Northern Finland. American Journal on Mental Retardation 108:19-31.

3. Lin, J.D., Wu, J.L., \& Yen, C.F. (2004). An exploratory study into health care policy for persons with intellectual disabilities in Taiwan. Journal of Intellectual Disability Research 48:252-261.

4. Cromby, J.J., Standen, P.J., \& Brown, D.J. (1996). The potentials of virtual environments in the education and training of people with learning disabilities. Journal of Intellectual Disability Research 40:489-501.

5. Standen, P.J., Cromby, J.J., \& Brown, D.J. (1998). Playing for real. Mental Health Care 1:412-415.

6. Standen, P.J., \& Ip, W.M.D. (2002). An evaluation of the use of virtual environments in improving choice reaction time in people with severe intellectual disabilities. In: Sharkey, P.M., Sik Lányi, C., \& Standen, P.J. (eds.), Proceedings of the 4th International Conference on Virtual Reality and Associated Technologies. Veszprém, Hungary: University of Reading, UK, pp. 19-24.

7. Standen, P.J., Lannen, T.L., \& Brown, D.J. (2002). Control of virtual environments for people with intellectual disabilities. In: Keates, S., Langdon, P., Clarkson, P.J., et al. (eds.), Universal access and assistive technology. London: Springer-Verlag, pp. 63-72.

8. Hall, J.D. (1993). Explorations of population expectations and stereotypes with relevance to design [Udergraduate thesis]. Department of Manufacturing Engineering, University of Nottingham, UK.

9. Brown, D.J., Kerr, S.J., \& Crosier, J. (1997). Appropriate input devices for students with learning and motor skills difficulties. Report to the National Council for Educational Technology, UK.

10. Standen, P.J., Brown, D.J., Proctor, T., et al. (2002). How tutors assist adults with learning disabilities to use virtual environments. Disability and Rehabilitation 24:570-577.

11. Lannen, T.J., Brown, D.J., \& Powell, H. (2002). Control of virtual environments for young people with learning difficulties. Disability and Rehabilitation 24:578-586.

12. Ruddle, R.A., \& Jones, D.M. (2001). Movement in cluttered environments. Presence 10:511-524.

13. Lannen, T.J. (2002). A multi-disciplinary approach to the control of virtual environments for young people with moderate to severe learning difficulties [Ph.D. dissertation]. Nottingham Trent University, Nottingham, UK.

Address reprint requests to: Dr. P.J. Standen Division of Rehabilitation and Ageing School of Community Health Sciences University of Nottingham B Floor

Medical School Queen's Medical Centre Nottingham NG7 2UH, UK

E-mail: P.Standen@nottingham.ac.uk 
Copyright of CyberPsychology \& Behavior is the property of Mary Ann Liebert. Inc. and its content may not be copied or emailed to multiple sites or posted to a listserv without the copyright holder's express written permission. However, users may print, download, or email articles for individual use. 